\title{
What happens
}

during a flu pandemic, when the people who are supposed to help

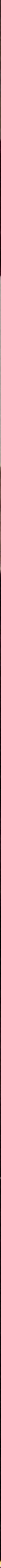

In the event of a flu pandemic, it is expected to take at least 4 - 6 months for a vaccine to become available.

How will you be protected? 


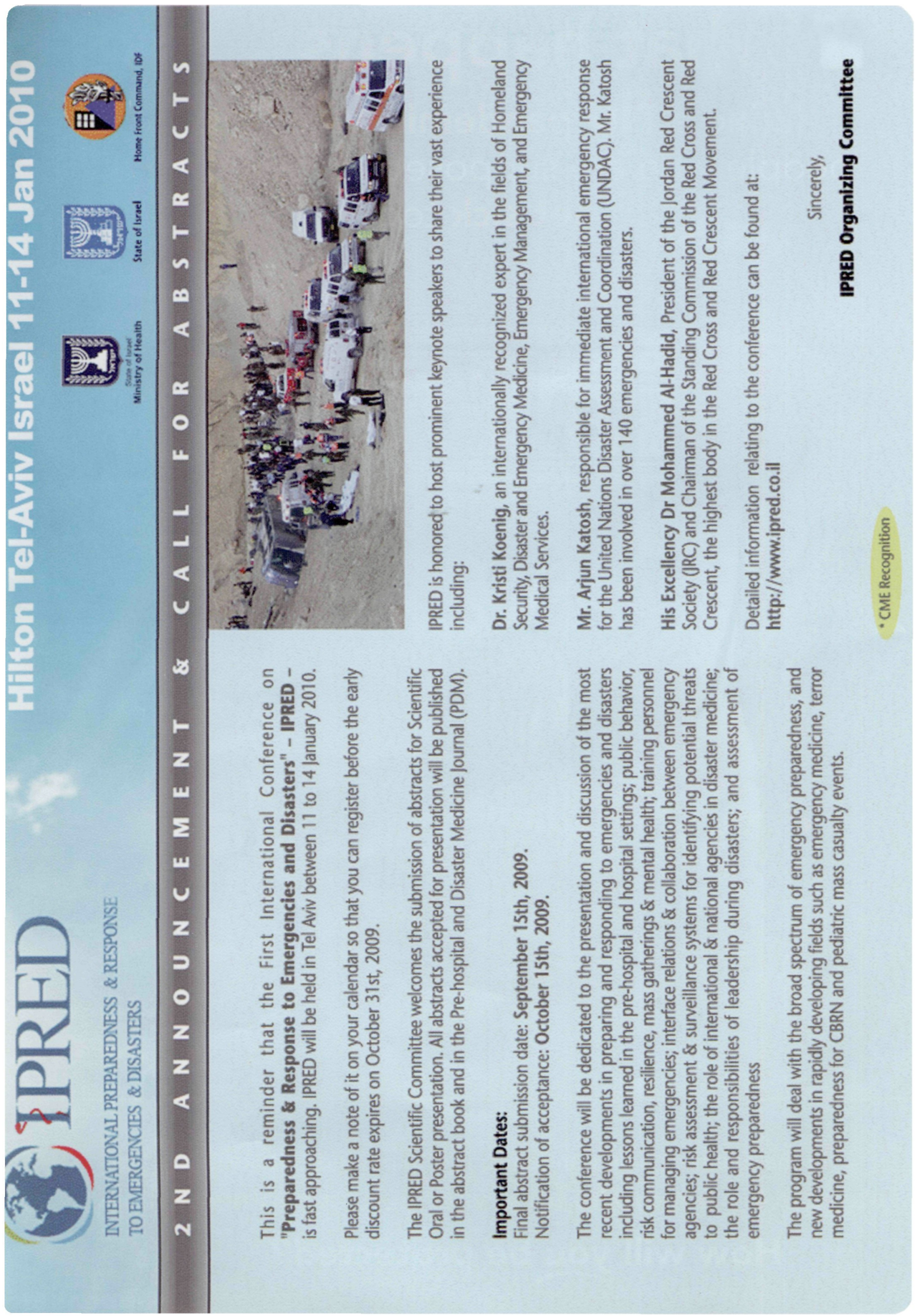




\section{Bringing Simulation to Life}

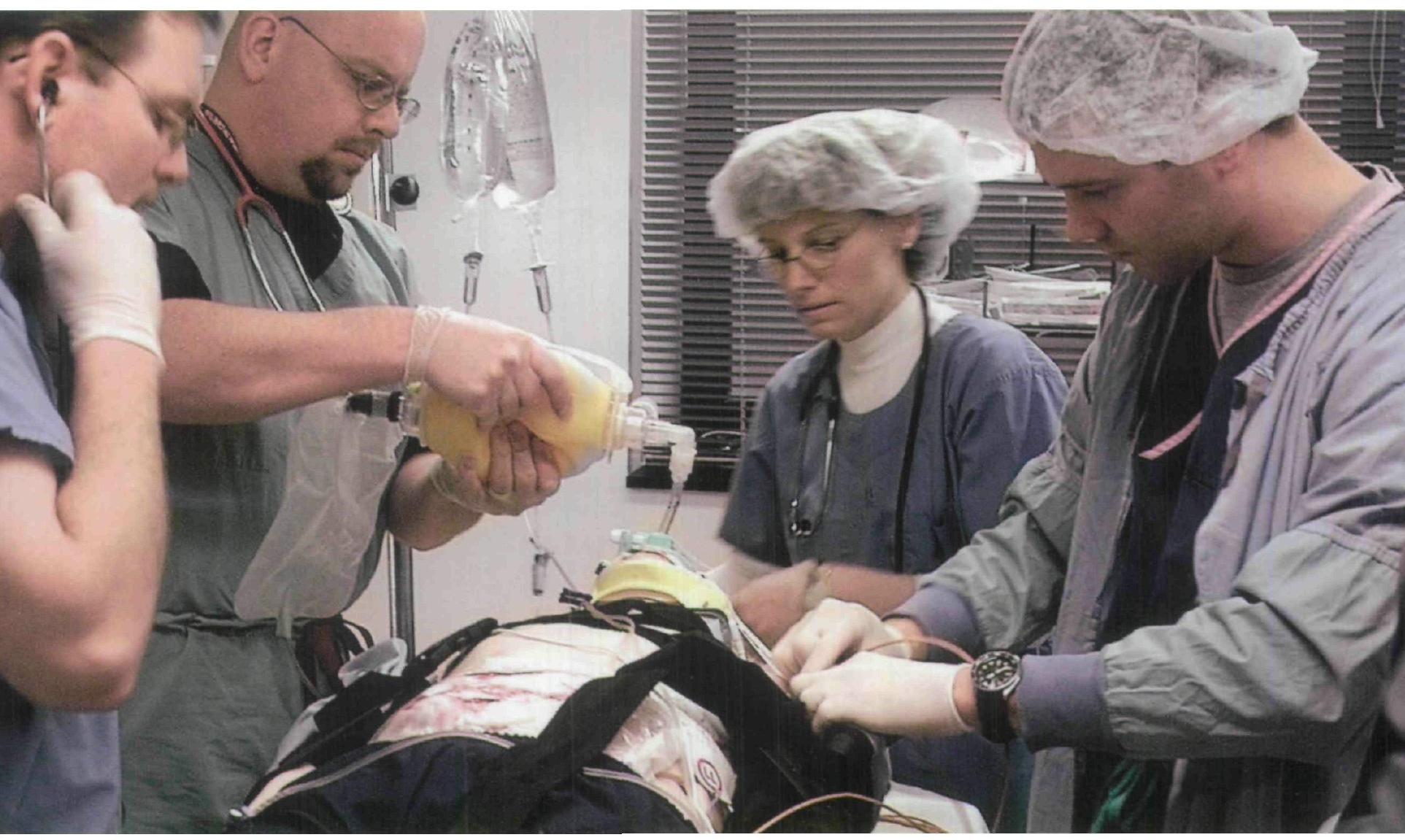

\section{$\operatorname{SimMan}{ }^{\circledR}$}

There is a growing awareness that health care is behind other high risk operations in its attention to ensuring basic safety and that there is a need to grasp the scale of the problem ${ }^{(1,2)}$.

Use of patient simulation is considered an important part of the solution as many scenarios can be presented including uncommon but critical situations where a rapid response is needed. Errors can be allowed to occur and reach their conclusion without any risk to a patient. Team member interactions and leadership can also be explored and developed.

Two manikin-based simulators from Laerdal, SimMan ${ }^{\circledR}$ and AirMan ${ }^{\circledR}$, represent a new generation of affordable and portable solutions to meet these needs.

References:

1) BMJ Volume 320. 18 March 2000

2) To Err is Human: Building a Safer Heakth System/Linda T. Kohn, Janet M. Comigar. and Molla S. Donaldson, Editors. $(2000$ by the National Academy of Sciences.

For more information visit wrwolaerdal.com/simman LAERDAL MEDICAL AS. P.O. Box 377, N-4002 Stavanger, Norway Tel.47-5। 5117 00. Fax 47-51 5235 57. E-mail laerdal.nomway@laerdal.no
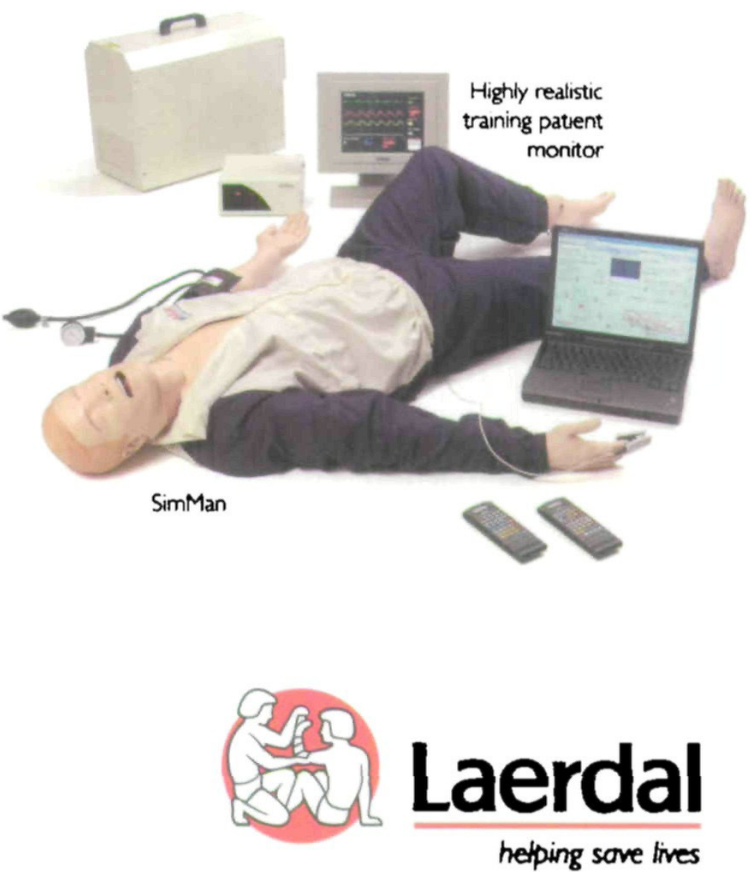


\section{GLOBAL DISASTER MANAGEMENT TEAM}

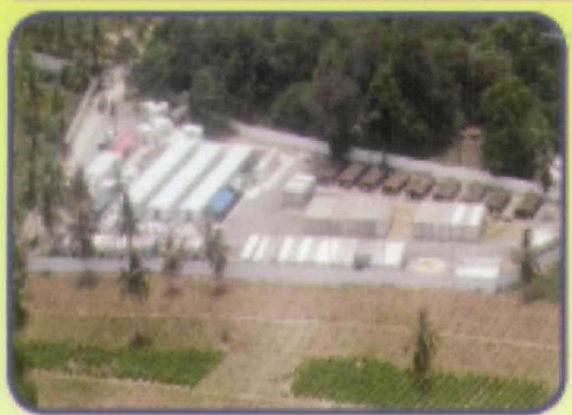

Thai Tsunami Victim Identification Centre

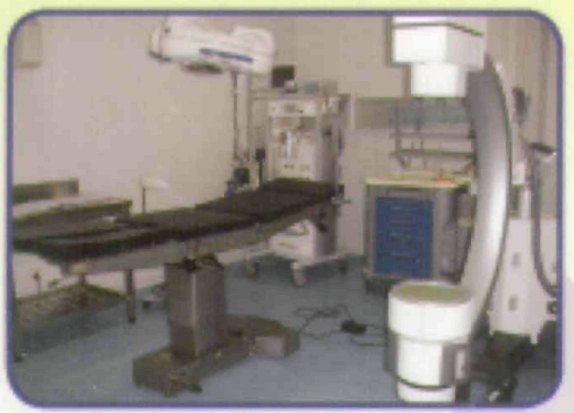

Inside OT in KATIKO Referral Hospital

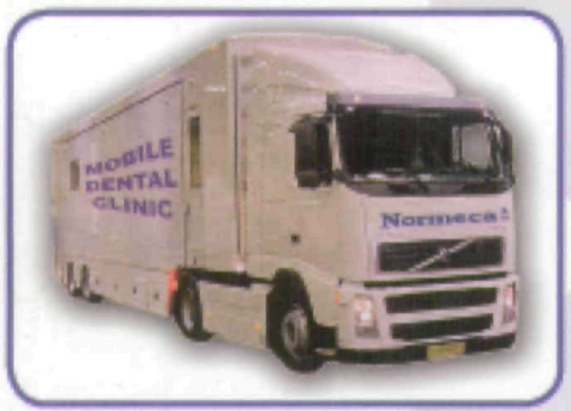

All kinds of clinies of hospitals in Multispace

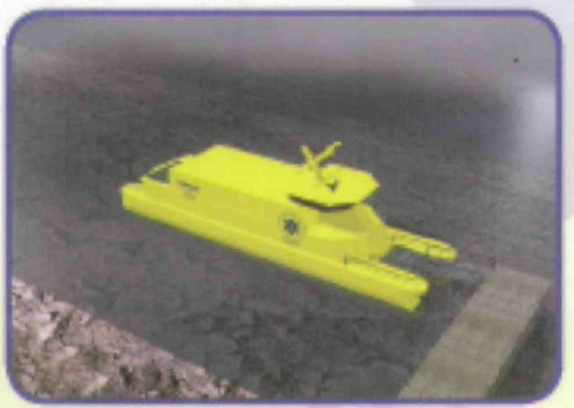

NorCat Floating Hospitals

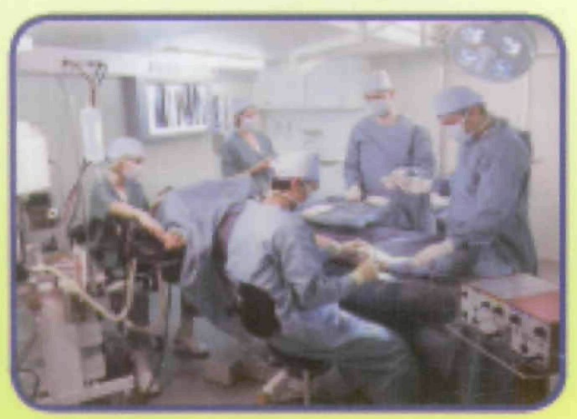

NorBase single and expandable eontainers

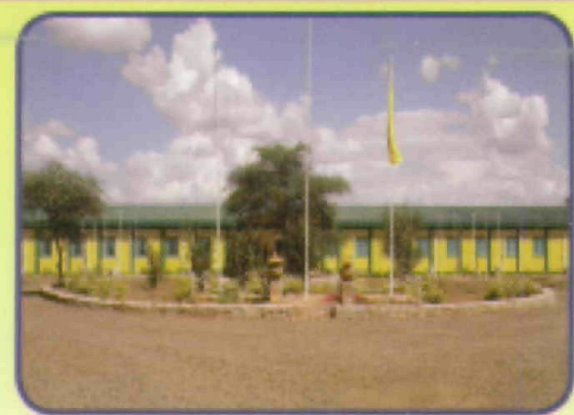

KATIKO Referral Hospital, Southem Sudan

\section{(9) Normeca ŝ}

Number One

in

the world

within

partly and turn key

solutions

incl.

Transportation,

Erection,

Management,

Training,

Maintenance,

Education, Administration,

Storage,

Out sourcing,

Medivac,

etc.

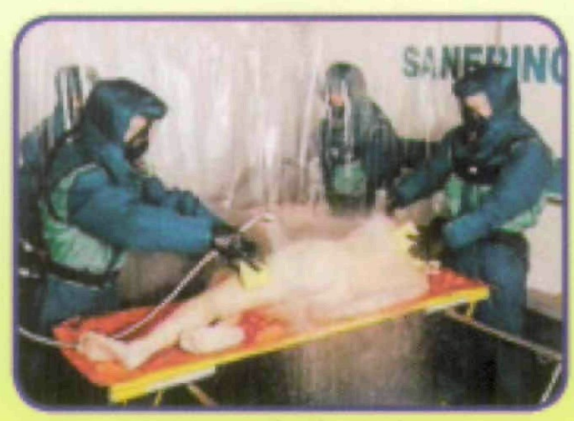

Decontamination Units

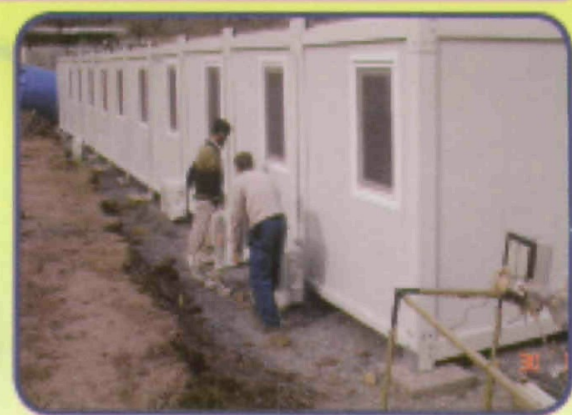

MSF Hospital, Hattian Bala, Pakistan

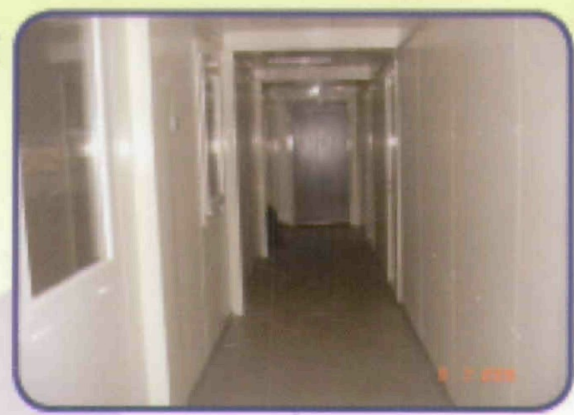

Inside MSF Hospital in Hattian Bala

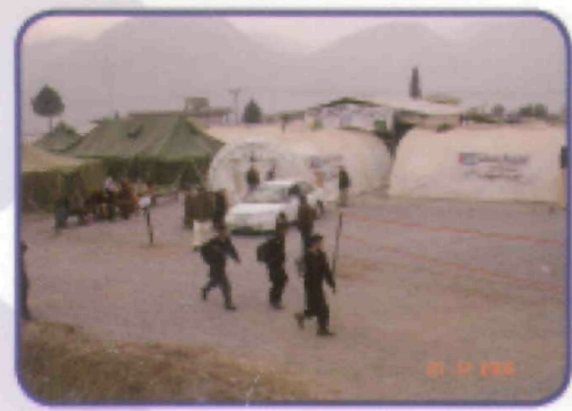

Cuban Hospital, Muzaffarabad, Pakistan

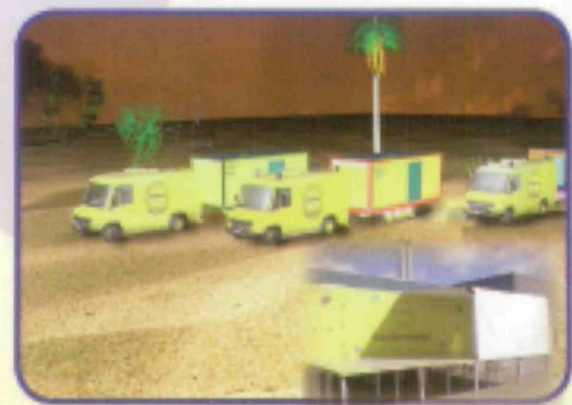

All kinds of Mobile Clinics

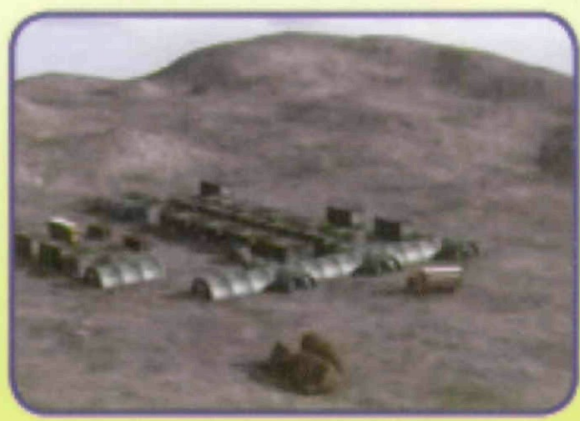

Norlense inflatable tents 